\title{
Absence of Diffusible Inhibitor of Glutamate Dehydrogenase in the Hepatocytes of Reye Syndrome Patients
}

\author{
ROBERT A. MITCHELL, BRIAN MCARTHUR, AND ASHOK P. SARNAIK \\ The Departments of Biochemistry and Pediatrics, Wayne State University School of Medicine and the Children's \\ Hospital of Michigan, Detroit, Michigan 48201
}

\begin{abstract}
Hepatic glutamate dehydrogenase (GDH) activity was measured in postmortem specimens obtained from two stage $V$ Reye syndrome patients and in three postmortem specimens of normal human liver. The Reye syndrome specimens showed the hepatic mitochondrial enzyme deficits in GDH and monoamine oxidase activities that are characteristic of Reye syndrome. GDH activity was linear with the amount of supernatant fraction added, both for Reye and normal liver preparations: moreover, the activities of mixtures of Reye and control supernatant fractions were the sums of the activities of the individual components. This means that the activity difference between Reye and normal GDH activity is not due to a diffusible inhibitor in the Reye hepatocytes or to an activator of GDH in the normal control hepatocytes. Serum obtained from six Reye cases during neurologic deterioration was added to normal hepatic GDH preparations to test for a serum inhibitor of FDH. Highly variable effects were found, with two serum samples producing marked inhibition and others showing weak inhibition, no effect, or stimulation of GDH activity. The inhibitor was not removed by charcoal treatment and most of the activity was retained by a 10,000 dalton Diaflo membrane, signifying either that the compound had a high molecular weight or that it was bound to serum protein. We conclude that the decreased activity of GDH in Reye hepatocytes is not due to an intracellular diffusible inhibitor, and that serum effects are quite variable and are not directly related to intracellular changes in GDH activity. (Pediatr Res 19: 110-112, 1985)
\end{abstract}

Abbreviations

GDH, glutamate dehydrogenase

MAO, monoamine oxidase

Elucidation of the early, latent hepatic changes in Reye syndrome is essential for a complete understanding of the disease. Prominent decreases in hepatic mitochondrial enzyme activity have been reported (1-6). Decreased mitochondrial enzyme activity does not appear to be due to the presence of abnormal forms of enzyme but rather to a decrease in activity of a normal

Received May 8, 1984; accepted August 29, 1984

Correspondence to Dr. Robert A. Mitchell, Biochemistry Department, Wayne State University, Scott Hall, 540 E. Canfield, Detroit, MI 48201.

This work was supported by the Reye Syndrome Study Center, Children's Hospital of Michigan, Detroit, MI. form of enzyme $(7,8)$. Mitochondrial-specific decreases in activity could arise from impaired mitochondrial biogenesis, enhanced mitochondrial degradation, or as recently proposed by Holt et al. (9), by an intracellular inhibitor. The proposal for such an hepatic inhibitor was based on the finding of a powerful inhibitor of serum GDH (EC 1.4.1.3) in the serum of 16 Reye syndrome patients. Since no evidence for a hepatic inhibitor was found in earlier experiments (6), we have reexamined liver specimens from Reye fatalities for evidence of a dialysable inhibitor of hepatic GDH, analogous to that found in serum. The in vitro effect of serum from six Reye syndrome patients on normal hepatic GDH activity was also studied.

\section{SUBJECTS AND METHODS}

Tissue and serum samples. Small specimens of liver obtained at autopsy (within $12 \mathrm{~h}$ of death) and stored in liquid nitrogen for periods up to $5 \mathrm{yr}$ were used for Reye and control enzyme measurements. The Reye specimens were from patients admitted to the Intensive Care Unit, Children's Hospital of Michigan, and whose diagnosis of Reye syndrome (based on case history, clinical, and laboratory findings) was confirmed by light and electron microscopic analysis of liver specimens.

Normal liver specimens were obtained (usually within $12 \mathrm{~h}$ of death) for victims of accidental death and who had no evidence of liver disorder. All specimens were obtained with the consent of parents or guardians.

Serum was obtained from six Reye syndrome cases during a phase of neurologic deterioration, i.e. following collection of the sample, the patient lapsed into a deeper stage of coma, as judged by the staging procedure of Lovejoy et al. (10). Serum samples were stored in liquid nitrogen up to $6 \mathrm{yr}$. Protocols for all experiments were approved in advance by the institutional review board of the Children's Hospital of Michigan.

Serum samples were filtered in a Diaflo Ultrafiltration cell using a PM 10 membrane to retain components with a mol wt $>10,000$ dalton.

Enzyme assays. GDH was measured spectrophotometrically by a highly reproducible, quantitative assay (6). The activity was measured in the $100,000 \times g$ supernatant fraction of tissue following homogenization of $20 \mathrm{mg}$ of tissue in $1 \mathrm{ml} 0.1 \mathrm{M}$ potassium phosphate buffer, $\mathrm{pH}$ 7.5. The activity was measured in the same buffer by following the conversion of $\alpha$-ketoglutarate into glutamate (in the absence of ADP) by the decrease in NADH absorbance. Normal and control tissue were compared by expressing the activity as IU $\times 1000 / \mathrm{mg}$ of supernatant protein. Btype MAO (EC 1.4.3.4) was measured in the $100,000 \times g$ pellet fraction and the activity was expressed as IU $\times 100,000 / \mathrm{mg}$ of pellet protein (6). 
Figure 1 is a composite diagram showing the enzyme activity added to the assay mixture (abscissa) and the activity actually measured (ordinate). The values for the abscissa were obtained by multiplying the specific enzyme activity in the supernatant fraction by the amount of protein added to the assay mixture. In the case of mixtures of Reye and normal liver samples the total activity was calculated as the sum of the individual components. The mixtures were prepared by adding equal volumes of Reye and control supernatant fractions to the assay cuvette, using arbitrary binary combinations of the two Reye and three control specimens.

The presence of an inhibitor capable of reversibly binding to GDH should be revealed in this type of plot as a marked deviation from linearity as the amount of supernatant solution is increased.

$$
\text { [Enzyme }]+[\text { Inhibitor }] \rightleftharpoons \text { [Enzyme.Inhibitor Complex }]
$$

This behavior follows from the above equation, which predicts that increasing [Enzyme] and [Inhibitor] by increasing the amount of inhibitor-containing supernatant fraction in the assay mixture should shift the distribution of the system toward the enzyme.inhibitor complex. The presence of a dissociable inhibitor in the Reye syndrome samples should thus appear as a deviation from linearity, i.e. the Reye (alone) samples at the higher added levels should lie below the line for the normal (alone) samples. This deviation did not occur.

It also follows from the equation that the addition of an inhibitor-containing Reye supernatant fraction to a normal, inhibitor-free fraction should produce inhibition of the normal enzyme, so that activities of such mixtures should be less than the sum of their separate components. This too should result in deviation from linearity, with the activities of all mixtures lying below the line for normal controls. This behavior was not observed. This lack of inhibition cannot be attributed to atypical behavior of the Reye liver specimens, as they were selected for study because they indeed showed the characteristic decreases in both GDH and MAO activities (Table 1).

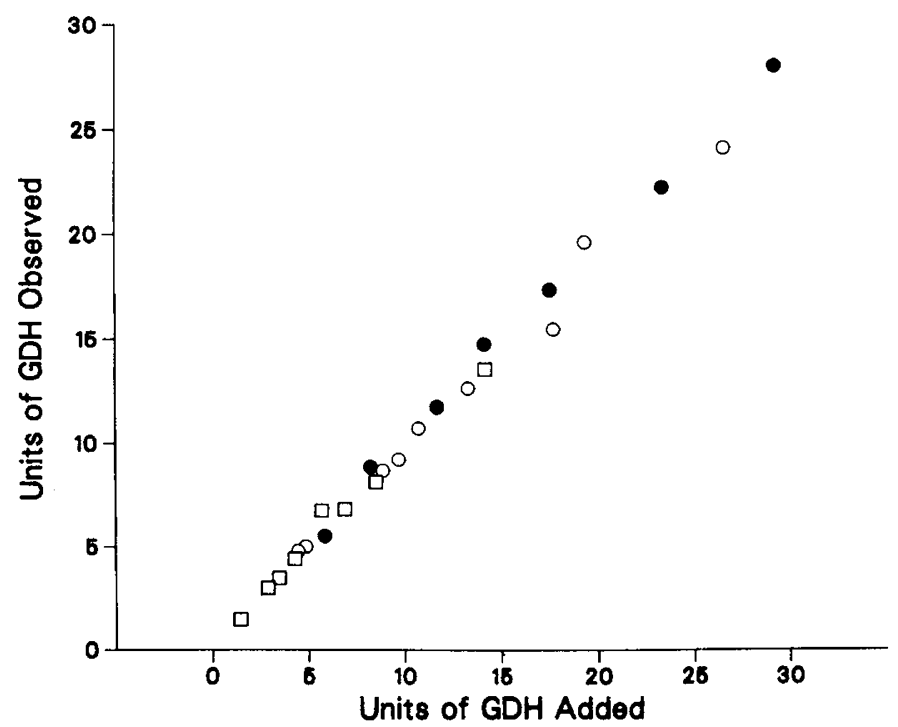

Fig. 1. Scatterplot showing units of hepatic GDH added (abscissa) and units of activity actually measured (ordinate) for three control and two Reye cases. Samples were added singly to the cuvette or in various combinations of control and Reye samples. Activities are expressed in IU $\times 1000 / \mathrm{mg}$ of supernatant protein (see Subjects and methods). $O$, normal liver; $\square$, Reye liver; $\bullet$, mixture containing approximately equal amounts of protein from a control and a Reye syndrome liver.
Table 1. Reye and control cases

\begin{tabular}{llccccc}
\hline & & & \multicolumn{3}{c}{$\begin{array}{c}\text { Hepatic activ- } \\
\text { ity* }\end{array}$} \\
\cline { 5 - 6 } ID & Cause of death & Age $(\mathrm{yr})$ & Sex & GDH & MAO \\
\hline & $\begin{array}{l}\text { Cardiopulmonary } \\
\text { arrest }\end{array}$ & 10.3 & M & 136 & 368 \\
C3 & $\begin{array}{l}\text { Cardiopulmonary } \\
\text { arrest }\end{array}$ & 1.1 & F & 158 & 300 \\
C4 & $\begin{array}{l}\text { Cerebral hemor- } \\
\text { rhage }\end{array}$ & 8.2 & M & 173 & 340 \\
R810 & $\begin{array}{l}\text { Reye syndrome } \\
\text { Reye syndrome }\end{array}$ & 7.6 & F & 85 & ND \\
R705 & 3.9 & F & 63 & ND \\
\hline
\end{tabular}

* Hepatic GDH and MAO activities are given as IU $\times 1000 / \mathrm{mg}$ of soluble protein and IU $\times 100,000 / \mathrm{mg}$ of particulate (i.e. pellet) protein, respectively. Hepatic MAO activity was not detectible in the Reye syndrome cases.

The presence of an inhibitor of GDH in serum was tested bv adding Reye serum to normal hepatic GDH. This procedure differs from that used by Holt et al. (9) who used serum GDH. Hepatic GDH was selected because serum GDH levels are quite low and the changes in absorbance are small compared with the background changes due to reduction of endogenous serum pyruvate (11). Also, it is possible that the serum GDH represents a modified form of the hepatic enzyme with differen. inhibitor sensitivity and that its properties differ from the intracellular form.

Two of the six Reye serum samples produced a marked inhibitory effect (about 50\% inhibition), others showed weak inhibition, no effect, weak stimulation $(10 \%)$, or strong stimulation (40\%). A strong stimulator of GDH (100\%) was found in a normal serum although this effector was not found in normal liver, as judged by the mixing experiments described earlier. The serum effects were obtained using $100 \mu \mathrm{l}$ of undiluted serum in a final volume of $3 \mathrm{ml}$ in the complete assay mixture.

The inhibitor was not removed by charcoal treatment, indicating it was not a nucleotide, and most of the activity (75\%) was retained by a membrane with a cutoff $>10,000$ daltons.

Addition of defatted bovine serum albumin appeared to prevent inhibition of GDH by the serum inhibitor (albumin alone had no effect). Possibly the inhibitor is a small molecule which binds both to albumin and to GDH and is scavenged by defatted bovine serum albumin.

\section{DISCUSSION}

A reduction of hepatic GDH and MAO activity by about 56 and $70 \%$, respectively, is highly characteristic of but not unique to Reye syndrome as judged from 20 Reye and 30 non-Reye control cases (12). It is possible that these hepatic changes precipitate subsequent neurologic changes, although a cause and effect relation has yet to be established. Nevertheless, establishing the nature and cause of the early, latent liver dysfunction might provide some insights into the cause and progression of the disease.

The semiautonomous nature of mitochondria has prompted speculation that the decrease in mitochondrial enzyme activity is a reflection of decreased steady-state levels of mitochondrial proteins (6). Such decreases could arise either by impairment of mitochondrial biogenesis, by enhanced mitochondrial protein breakdown, or by a combination of both effects. However, other possibilities such as the presence of intracellular inhibitors of mitochondrial enzyme activity have not been excluded. Thus, the suggestion by Holt et al. (9) that the low activity of intracellular GDH activity results from an in vivo inhibition of GDH by 
a potent inhibitor, possibly a nucleotide, merits careful attention.

The results shown in Figure 1 provide no evidence for a dissociable inhibitor of GDH in Reye syndrome hepatocytes. The strict linearity between units of GDH activity added and units of activity observed over a wide range of protein concentrations, for Reye specimens measured singly or in the presence of GDH from normal liver, is incompatible with this type of inhibition. If the approximately $50 \%$ decrease in GDH activity in Reye syndrome is caused by the conversion of active enzyme into an enzyme.inhibitor complex, then the addition of 100 units of normal hepatic enzyme to the same cuvette should produce a similar degree of inhibition so that mixtures of control and Reye hepatic enzymes would display about two-thirds of the summated, individual activities. A deviation of this magnitude would be detected easily but did not occur.

Moreover, since GDH is only one of the mitochondrial enzymes known to be diminished in activity in Reye syndrome, if in vivo inhibition were to be a general explanation for the mitochondrial deficits in Reye syndrome, there would have to be an inhibitor for each affected enzyme, since the inhibitor described by Holt et al. (9) was specific for GDH. Although two of six serum samples obtained from Reye syndrome patients during neurologic deterioration contained a substance inhibitory to normal hepatic GDH, the other samples produced effects ranging from weak inhibition to stimulation.

We conclude that the decreased activity of hepatic GDH (and by analogy, other mitochondrial enzyme activities) is not the result of an intracellular inhibitor. The in vitro inhibition or stimulation of normal hepatic GDH by substances present in Reye syndrome or control serum is neither directly related to hepatic intracellular events nor to neurologic status.

\section{REFERENCES}

1. Brown T, Hug G, Lansky L, Bove K, Scneve A, Ryan M, Brown H, Schubert WK, Partin JC, Lloyd-Still J 1976 Transiently reduced activity of carbamyl phosphate synthetase and ornithine transcarbamylase in the liver of children with Reye's syndrome. N Engl J Med 294:861-867

2. Kang ES, Gerald PS 1972 Hyperammonemia and Reye's syndrome. N Engl J Med 286:1216-1217

3. Sinatra F, Yoshida T, Applebaum M, Mason W, Hoogenrad NJ, Sunshine P 1975 Abnormalities of carbamyl phosphate synthetase and ornithine transcarbamylase in liver of patients with Reye's syndrome. Pediatr Res 9:829833

4. Thaler MM, Hoogenraad NJ, Boswell M 1974 Reye's syndrome due to a novel protein-tolerant variant of ornithine transcarbamylase deficiency. Lance 2:438-440

5. Robinson BH, Gall DG, Cutz E 1977 Deficient activity of hepatic pyruvate dehydrogenase and pyruvate carboxylase in Reye' syndrome. Pediatr Res 11:279-281

6. Mitchell RA, Ram ML, Arcinue EL, Chang CH 1980 Comparison of cytosolic and mitochondrial hepatic enzyme alterations in Reye syndrome. Pediatr Res 14:1216-1221

7. Snodgrass PJ, DeLong GR 1976 Urea-cycle enzyme deficiencies and an increased nitrogen load producing hyperammonemia in Reye's syndrome. $\mathrm{N}$ Engl J Med 294:855-860

8. Pierson DL, Cox SL, Gilbert BE 1977 Human ornithine transcarbamylase: purification and characterization of the enzyme from normal liver and the liver of a Reye's syndrome patient. J Biol Chem 252:6464-6469

9. Holt JT, Arvan DA, Mayer TK 1983 Masking by enzyme inhibitor of raised serum glutamate dehydrogenase activity in Reye's syndrome. Lancet 2:4-7

10. Lovejoy FH, Smith AL, Bresman MJ, Wood JN, Victor DI, Adams PC 1974 Clinical staging in Reye syndrome. Am J Dis Child 128:36-41

11. Schmidt E 1974 Glutamate dehydrogenase UV-assay. In: Bergmeyer HU (ed) Methods in Enzymatic Analysis, Vol 2, 2nd English ed. Academic Press, New York, pp 650-656

12. Mitchell RA, Arcinue EL, Partin JC, Partin JS, Ram ML, Chang CH, Smialek J, Sarnaik A. 1985 Quantitative evaluation of the extent of hepatic enzyme changes in Reye syndrome compared with normal liver or with non-Reye liver disorders; objective criteria for animal models. Pediatr Res 19:19-22

\title{
Evidence for Decreased Secretion of Gonadotropin-Releasing Hormone in Pubertal Boys during Short-Term Testosterone Treatment
}

\author{
ROBERT P. KELCH, NANCY J. HOPWOOD, SUEELLYN SAUDER, AND JOHN C. MARSHALL \\ Departments of Pediatrics and Internal Medicine, Reproductive Endocrinology Program, University of Michigan, \\ Ann Arbor, Michigan 48109
}

\begin{abstract}
Information about the site(s) of action as well as the age-dependent effects of sex steroids on gonadotropin-releasing hormone and gonadotropin secretion during human puberty is limited. To begin to address these questions, we evaluated the effects of a depot preparation of testosterone (testosterone enanthate) on gonadotropin secretion and pituitary responses to synthetic GnRH in 10,
\end{abstract}

Received May 21, 1984; accepted August 29, 1984

All correspondence and requests for reprints should be addressed to Robert $P$. Kelch, M.D., Pediatric Endocrinology, D1 109 Medical Professional Building, University of Michigan, Ann Arbor, MI 48109-0010.

Supported by Grants 5M01RR42 and HD16000.

Presented in part at the meeting of the Society for Pediatric Research, Washington, D.C., May, 1983. early to mid-pubertal boys who had either isolated $\mathrm{GH}$ deficiency $(n-2)$ or delayed adolescent maturation $(n-8)$. Chronological and bone age ranges were $131 / 12-16 \frac{1}{1 / 12}$ and 11-14 yr, respectively. Frequent blood withdrawal studies (every 20 min for 20 consecutive $h$ ) were performed in the Clinical Research Center over two consecutive weekends. Following each study, gonadotropin responses to GnRH $(0.25 \mu \mathrm{g} / \mathrm{kg}$ iv bolus) were determined. During the initial study, all boys showed a sleep-entrained increase in luteinizing hormone (LH) and testosterone (T) secretion; mean nocturnal concentrations of $\mathrm{LH}$ and $\mathrm{T}$ were 2.3 -fold greater than daytime values. At the end of the first study, testosterone enanthate was given im $\left(0,25,50\right.$, or $\left.75 \mathrm{mg} / \mathrm{m}^{2}\right)$. Six days later, mean plasma $T$ concentrations were in the 